\title{
Health-related quality of life after radical cystectomy
}

\author{
Hoon Choi, Jae Young Park, Jae Hyun Bae, Bum Sik Tae \\ Department of Urology, Korea University Medical Center, Korea University School of Medicine, Ansan, Korea \\ Contributions: (I) Conception and design: H Choi, BS Tae; (II) Administrative support: JH Bae; (III) Provision of study materials or patients: H Choi, \\ JY Park, BS Tae; (IV) Collection and assembly of data: All authors; (V) Data analysis and interpretation: All authors; (VI) Manuscript writing: All \\ authors; (VII) Final approval of manuscript: All authors. \\ Correspondence to: Bum Sik Tae. Department of Urology, Korea University Ansan Hospital, Korea University College of Medicine, 123 Jeokgeum-ro, \\ Danwon-gu, Ansan 15355, Korea. Email: bumsik4ever@hanmail.net.
}

\begin{abstract}
Herein, we review the assessment of quality-of-life (QoL) in radical cystectomy (RC) patients, summarize the result of studies for different surgical approaches, and provide an overview of patient management, as well as other considerations. In this review article, we reviewed the QoL research and research tools for patients undergoing $\mathrm{RC}$, including urinary diversion methods, gender differences, and surgical methods (open surgery vs. robotic surgery). This narrative review focused primarily on articles indexed in PubMed, Embase, Scopus, and Google Scholar databases. We did not used formal search strategy and meta-analysis was not performed.
\end{abstract}

Keywords: Urothelial cell carcinoma; radical cystectomy (RC); health; quality of life

Submitted Oct 27, 2019. Accepted for publication Dec 31, 2019.

doi: $10.21037 /$ tau.2020.02.01

View this article at: http://dx.doi.org/10.21037/tau.2020.02.01

\section{Introduction}

Bladder cancer (BC) is the 9th most common malignancy amongst South Korean men and is among the most expensive malignancies to manage $(1,2)$. BC can be classified into non-muscle invasive BC (NMIBC) and muscle invasive BC (MIBC), according to whether the muscle layer has been infiltrated. While NMIBC treatment is mostly bladder-conserving (for example: endoscopic surgery), radical cystectomy (RC) is considered the standard of care for muscle invasive disease (3). Procedure-related complications and readmission rates following $\mathrm{RC}$ are high, which can reduce the quality-oflife (QoL) in patients (4). In addition, RC may negatively impact urinary, bowel, and sexual function, as well as affect body image, which can decrease QoL and lead to psychological problems (5-7).

Although many previous studies have examined the effect of RC on the QoL of patients, high-quality studies are lacking due to methodological limitations. Because of the nature of $\mathrm{BC}$, it is difficult to conduct randomized controlled trials (RCTs). Therefore, the limitations of most existing studies on patients' QoL following RC include cross-sectional designs, small sample sizes, and inadequate confounding control. However, with the recent publication of high-quality studies using various surveys, there is a growing interest regarding QoL in patients undergoing RC. In this review article, we reviewed the QoL research and research tools for patients undergoing RC, including urinary diversion methods, gender differences, and surgical methods (open surgery $v s$. robotic surgery).

\section{Methods}

We performed a narrative review of relevant research. While no formal search strategy was employed, we primarily used the following search terms to identify relevant sources: bladder cancer, urothelial carcinoma, radical cystectomy, QoL. PubMed, Scopus, Google Scholar and Embase databases were searched to identify potentially relevant published literature. The current search was performed in August 2019. References from relevant sources were examined to identify additional sources for this review, and a synopsis of relevant 
Table 1 Available quality-of-life instruments for muscle invasive bladder cancer

\begin{tabular}{|c|c|c|c|c|c|c|c|c|}
\hline Tool & Nation & Institution & Domain & $\begin{array}{l}\text { Number of } \\
\text { items }\end{array}$ & Validated & Reliable & $\begin{array}{l}\text { Bladder cancer } \\
\text { specific }\end{array}$ & Reference \\
\hline IONB-PRO & Italy & $\begin{array}{l}\text { Trieste } \\
\text { University }\end{array}$ & $\begin{array}{l}\text { Symptoms: neobladder } \\
\text { self-management, } \\
\text { activities of daily living, } \\
\text { emotional issues, social } \\
\text { issues, sleep/fatigue }\end{array}$ & 23 & Yes & Yes & Yes & (10) \\
\hline FACT-VCI & USA & $\begin{array}{l}\text { Vanderbilt } \\
\text { University }\end{array}$ & $\begin{array}{l}\text { See FACT-G: urinary, } \\
\text { bowel, sexual function }\end{array}$ & 45 & Yes & Yes & $\begin{array}{l}\text { Yes- } \\
\text { cystectomy } \\
\text { specific }\end{array}$ & (8) \\
\hline $\begin{array}{l}\text { QLQ-BLM } 30 \\
\text { module }\end{array}$ & Multination & EORTC & $\begin{array}{l}\text { Urinary: bowel, sexual } \\
\text { function }\end{array}$ & 30 & Yes & Yes & Yes & (12) \\
\hline FACT-G & USA & FACIT & $\begin{array}{l}\text { Physical: social, } \\
\text { emotion, function }\end{array}$ & 27 & Yes & Yes & No & (13) \\
\hline QLQ-C30 & Multination & EORTC & $\begin{array}{l}5 \text { functional scales; } \\
3 \text { symptom scales; } \\
1 \text { Global Health/QoL } \\
\text { scale }\end{array}$ & 30 & Yes & Yes & No & (12) \\
\hline
\end{tabular}

IONB-PRO, Ileal Orthotopic Neobladder-Patient-reported Outcome; EORTC, European Organization for the Research and Treatment of Cancer; FACIT, The Functional Assessment of Chronic Illness Therapy; FACT-BL, Functional Assessment of Cancer Therapy-Bladder Cancer, FACT-VCI, Functional Assessment of Cancer Therapy-Vanderbilt Cystectomy Index; FACT-G, Functional Assessment of Cancer Therapy-General; QLQ-BLM30, EORTC quality-of-life core questionnaire-bladder cancer muscle invasive.

references was created. The authors are accountable for all aspects of the work in ensuring that questions related to the accuracy or integrity of any part of the work are appropriately investigated and resolved.

\section{QoL assessment in patients undergone RC}

It is difficult to evaluate the QoL in patients who have undergone RC. This is because the scope, method of surgical treatment, and strategy of treatment vary according to tumor stage. Second, the method of urinary diversion varies depending on the patient's indication. Therefore, it is difficult to assume that all participants included in an RCT were assessed in a similar fashion. Further, there is risk of selection bias. Nevertheless, there is an increasing need for novel technologies or approaches to BC management (such as enhanced recovery progress), that will improve BC treatment outcomes and QoL.

Various assessment instruments have been developed to quantify QoL in BC patients after RC. Examples include the FACT-BL (Functional Assessment of Cancer Therapy Scale Bladder Cancer), QLQ-BLM [EORTC (European Organisation for Research and Treatment of Cancer) Invasive Bladder Cancer Module], BIS (Body Image Scale), and BCI (Bladder Cancer Index). Other general healthrelated QoL (HRQoL) instruments, such as the RAND Medical Outcomes Study 36-Item Health Survey (SF36) ${ }^{\circledR}, \mathrm{VR}-12^{\circledR}$ and QLQ-C30 (EORTC Quality of Life Core Questionnaire), have also been used to evaluate QoL in patients with $\mathrm{BC}(8,9)$. Although not all these tools are suitable, several validated instruments have been adapted to evaluate QoL after RC in patients with BC (Table 1).

Various psychologically validated survey instruments assess general QoL and can be used in patients with BC. The SF-36 is the most well established and widely used general QoL instrument. This survey consists of 36 questions across 8 distinct functional domains, including vitality, bodily pain, general health perceptions, physical 
function, physical role functioning, social role functioning, emotional role functioning, and mental health (15). Although the SF-36 does not contain specific subjects related to BC, various studies have used this tool to assess general QoL in BC patients undergoing RC $(16,17)$.

The FACT-BL is a 39-item survey that includes all items on the FACT-G questionnaire (a generic QoL measure) as well as 12 specific items that cover constitutional symptoms $(13,14)$. The FACT-BL assesses urinary symptoms, bowel function, sexual function, body image, and stoma care. In addition, various studies validating the FACT-BL have been published (18-20). The Vanderbilt Cystectomy Index (FACT-VCI) is another BC-specific questionnaire that was created at the Vanderbilt University. The FACTVCI focuses on urinary function and its effects on social interaction as well as on physical and sexual activities after RC (8).

The BCI was designed to include patients with any stage of $\mathrm{BC}$ and is made up of 34 items grouped into the following three domains: urinary, sexual, and bowel function. Each major domain is further broken down into two subdomains (bother and functions). Compared to other instruments, the BCI is BC-specific, targets symptoms commonly associated with $\mathrm{BC}$ treatment, and is responsive (sensitive) to differences (11). For RC with ileal conduit (IC) patients, the BCI measures function and appliance of stoma, as well as urine leakage and skin problem. Individual item responses are based on a Likert scale, and the composite score is standardized using a scale from 0 to 100 (with higher scores indicating better function). However, the BCI has some limitations as follows: correlation analysis between the BCI and other HRQoL measures has shown that the BCI measures previously under-recognized aspects of HRQoL, in addition to components consistent with external criteria. In addition, the BCI lacks a core module to measure general QoL. It also lacks items that are specific to gender, urinary diversion, and body image (21).

The EORTC QLQ-C30 survey has been widely used to measure QoL in BC patients. Specifically, the EORTC QLQ-BLM30 is an adaptation of the EORTC QLQ-C30 and includes 30 additional items specific to MIBC (12). The EORTC QLQ-BLM30 also includes items specific to urinary diversion (incontinence and self-clean intermittent catheterization), urostomy, and sex (related to sexual function). The scoring method of the QLQ-BLM30 is similar to that of the symptom and function scale of the QLQ-C30. All the scales and single-item measurements range from 0 to 100 .

\section{Urinary diversion method}

RC often causes a significant change to the patient's lifestyle, since the native bladder is removed and the intestines are used to perform the urinary diversion. Patients who undergo the IC method experience the disadvantage of a continuous abdominal stoma; however, they do not develop problems related to urinary retention or incontinence $(22,23)$. Conversely, patients who undergo the orthotopic neobladder (ONB) method do not require an abdominal stoma and have the advantage of being able to void through the urethra. However, these patients are at risk of QoL reduction due to urinary retention or incontinence. There is also a risk of further complications related to formation of the neobladder. Since there is no difference in QoL or oncologic outcomes between the IC and ONB methods, patients who are eligible for either procedure (and their urologists) face a sensitive decision based largely on preference (24). There is still controversy amongst clinicians and researchers regarding the most effective urinary diversion method for RC patients. For example, some researchers argue that orthotopic diversion preserve body image but are associated with later complications. They claim that urinary incontinent, namely the IC method, provides the most effective and safest method of urinary diversion (25). However, other studies show that the ONB method is associated with better QoL scores compared to the IC method $(17,26)$ (Table 2).

Most previous publications on QoL in RC patients are retrospective studies limited by methodologic bias, insufficient statistical power, cross-sectional design, and a lack of validated instruments $(34,35)$. However, as mentioned above, relatively recent and validated BCspecific questionnaires have markedly improved our ability to assess the experience of patients who have undergone urinary diversion. For example, the authors of one crosssectional study sent questionnaires to patients who had previously undergone $\mathrm{RC}$, and observed that the overall sexual and bowel function was similar between ONB and IC patients (15). However, urinary function scores were lower in the ONB group than in the IC group, whereas urinary bother scores were similar between the two groups. Interestingly, both the ONB and IC groups reported a marked worsening of body image [assessed using the EORTC body image scale (BIS)], postoperatively compared with baseline. Although body image scores returned to baseline in the IC patients after several years, body image scores in the ONB group did not return to baseline $(7,11)$. 
Table 2 Postoperative health-related QoL change in study of radical cystectomy and urinary diversion

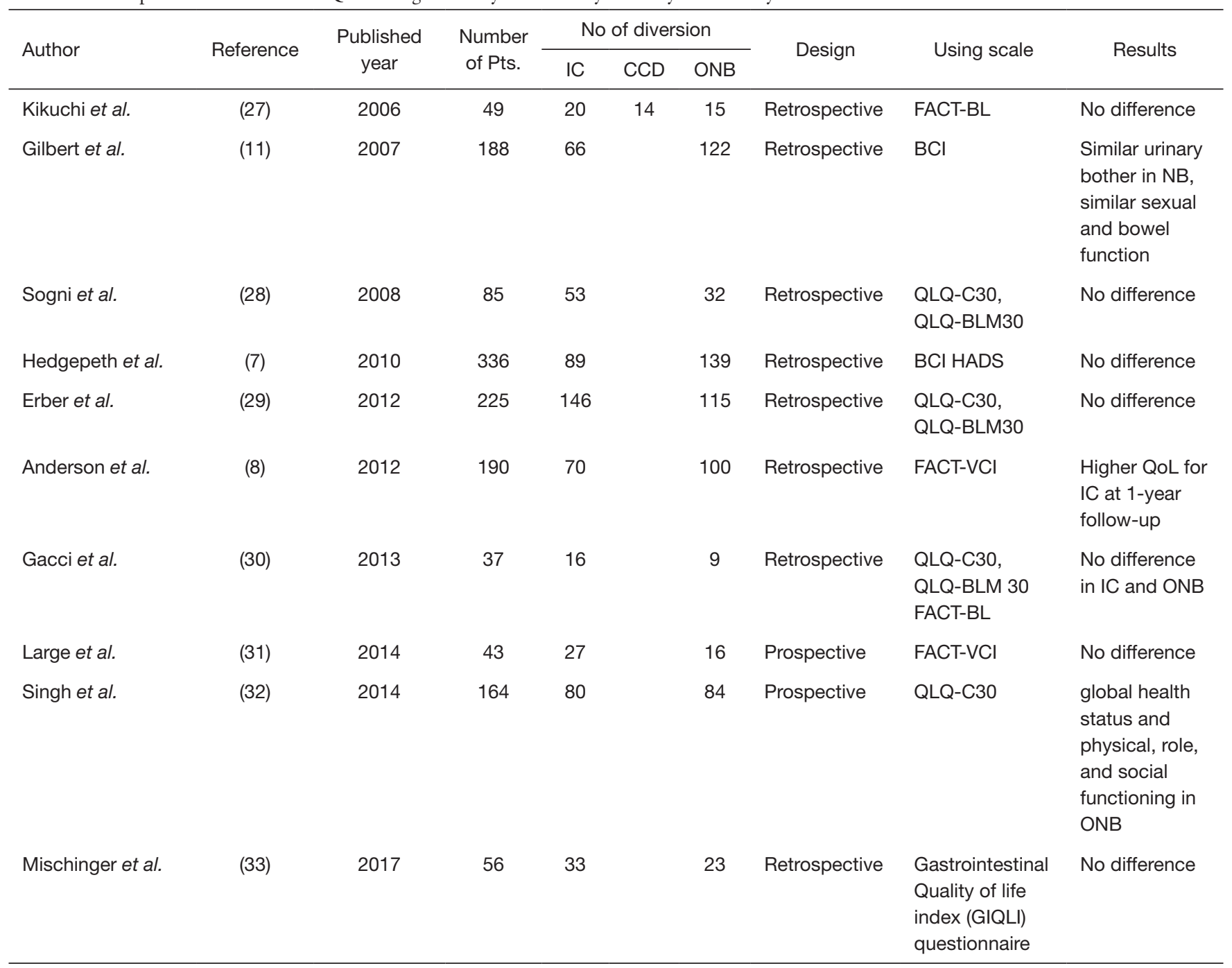

FACT-BL, Functional Assessment of Cancer Therapy-Bladder Cancer; BCl, Bladder cancer index; FACT-VCl, Functional Assessment of Cancer Therapy-Vanderbilt Cystectomy Index; QLQ-BLM30, EORTC quality-of-life core questionnaire-bladder cancer muscle invasive, QLQ-C30, EORTC core quality of life questionnaire; HADS, hospital anxiety and depression scale.

Numerous studies have demonstrated that the ONB method does not result in superior QoL scores compared to the IC method. However, Singh et al. recently conducted a prospective study in which they showed that the ONB method is associated with improvements in several QoL domains (32). They demonstrate that patients who had undergone the ONB method had significantly greater global health status and QoL than patients who had undergone the IC method at all time points $(6,12$, and 18 months after surgery). In contrast, Siracusano et al. recently showed (in female cancer survivors) that there was no significant difference in QoL between ONB and IC patients, with the exception of financial difficulties, which affected ONB patients significantly more than IC patients. They also argue that, where QoL is concerned, the body of research does not appear (thus far) to clearly support one urinary diversion procedure over the other (36).

The effect of urinary diversion procedure on sexual function is not established, but several comparison studies exist. Despite their small sample size and limited study design, two studies reported that ONB patients had better sexual function outcomes than IC patients $(5,7)$. Only $3 \%$ of IC patients could maintain a penile erection when compared with $23 \%$ of ONB patients, despite similar sexual desire. 
However, because of study bias and a lack of evidence, additional well-controlled and properly designed studies are needed to validate this finding. Other studies did not show meaningful differences in sexual function between patients who have undergone different urinary diversion procedures, but regardless, the chance of any man recovering significant sexual function recovery following RC is low (36-38).

\section{QoL following open vs, robotic surgery}

The need for minimally invasive surgery has led to the development of robotic surgery. In urological surgery, a robotic approach is the dominant method for patients undergoing radical prostatectomy in the developed world $(39,40)$. As with all minimally invasive procedures, the primary benefit of robot-assisted surgery is the potential for decreased morbidity and an easier recovery. Technical advances and the ability to use smaller incisions may also reduce complications and decrease hospital length-of-stay. Although the application and development of robot-assisted RC (RARC) surgery is progressing, it has lagged behind prostatectomy or nephrectomy surgery (2).

Most previous described RARCs are performed using a combined approach wherein the cystectomy and pelvic lymph node dissection are conducted using a minimally invasive surgery approach, and the urinary diversion is then created through an open incision (41). However, the totally intracorporeal ONB method has gained interest as a reproducible technique with operative efficiency and acceptable perioperative outcomes $(41,42)$. It is not clear that patients' postoperative QoL is better following RARC compared to open surgery. In a small-scale prospective study, Poch et al. evaluated changes in BCI and BIS scores, and HRQoL outcomes, after RARC. Within the QoL domains, urinary function was the first to return to baseline 2 months after surgery, followed by bowel function 4 months postoperatively (43). In addition, initial postoperative declines in the sexual function and body image domains returned to baseline 16-24 months postoperatively.

Niranjan et al. recently conducted a meta-analysis of five RCTs, which revealed no difference in oncologic outcomes, side effects, or QoL profiles between the different types of urinary diversion methods (44). The primary outcome was QoL 90 days following RC, as measured by the FACT, a validated QoL instrument. Only three of the five studies assessed QoL 90 days after RC; within these three studies, a total of 271 participants adequately completed the questionnaires. The results of this meta-analysis showed that RARC and open radical cystectomy (ORC) were comparable (standardized mean difference: -0.03 ; $95 \%$ CI: -0.27 to -0.21$)$.

However, it is important to point out all five studies in the meta-analysis performed UD using the extracorporeal method. As mentioned above, the totally intracorporeal UD method has recently gained popularity because it has the advantage of not needing an extra incision to create the neobladder. However, the intracorporeal UD method was associated with higher grade complications than the extracorporeal UD method (45). Recently, a multicenter study demonstrated that long-term oncologic outcomes after RARC with ICUD appear similar to a recent robotic series with extracorporeal diversion and historical open experiences (46).

Recently, a well-controlled and properly designed prospective study on the efficacy of robotic surgery was published (47). Known as the 'RAZOR' trial, this multicenter, noninferiority, phase III study compared oncological outcomes, complications, and healthrelated QoL in patients treated with open versus robotic cystectomy. Three hundred and twenty patients with T1T4, N0-N1, and M0 BC are currently enrolled. QoL outcomes were assessed at baseline, 3 months post-surgery, and 6 months post-surgery using the Short Form- 8 and the FACT-VCI questionnaires. The authors observed no significant differences in FACT-VCI between the treatment arms at any timepoint. In patients who received RARC, the mean estimated score for emotional wellbeing was significantly higher at 3 months $(\mathrm{P}=0.0007)$ and 6 months $(\mathrm{P}=0.0014)$ post-surgery compared to baseline. However, both groups demonstrated a significant improvement in mean total FACT-VCI scores 6 months after surgery compared with baseline. Overall, there was no difference in QoL between the open cystectomy and RARC groups. However, one limitation of this RCT is that all urinary diversions were extracorporeal.

Kimura et al. recently conducted a meta-analysis comparing perioperative complications and HRQoL between patients receiving RARC and ORC (48). They found that only six studies (of which, only three were RCTs) assessed HRQoL before and after surgery. However, it was not possible to carry out a meta-analysis of the HRQoL outcomes due to the heterogeneity of assessment tools used in the studies. However, most studies concluded that QoL outcomes following RARC were comparable to those of ORC (Table 3). 


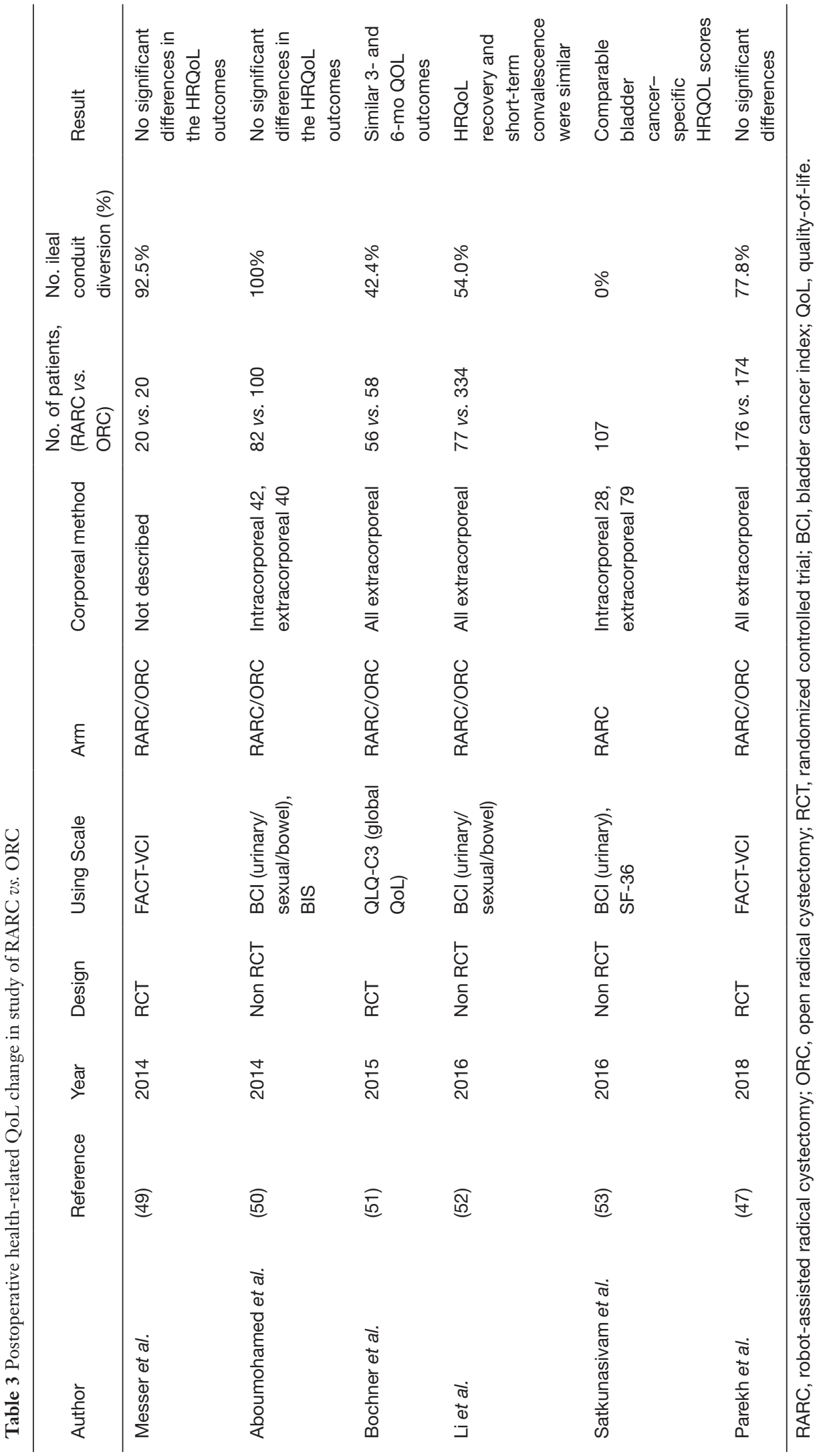


One prospective study evaluated the difference in QoL after RC in ICUD versus RC in ECUD (53). Among 107 patients, 28 patients underwent RC in ICUD. Mean BCI scores for urinary function $(\mathrm{P}=0.58)$ and urinary bother $(\mathrm{P}=0.31)$ were comparable between the groups. In addition, using a multivariable analysis, the authors showed that the use of the corporeal method was not correlated with BCI scores. However, few high-quality studies (with high levels of evidence) have investigated QoL after RC in ICUD. In addition, the nerve sparing technique is known to have a greater effect on postoperative sexual function recovery than UD (54).

\section{QoL in women}

QoL after RC are sparse and poorly defined because most prospective studies have excluded women, had small sample sizes, various surgical techniques, and lacked validated instruments and standard definitions. Nevertheless, QoL after RC is a particularly important issue for women, especially those who are socially or sexually active. Smith et al. performed the first systematic review that assessed functional outcomes in these three domains in women (55). They included publications that addressed urinary function (34 studies), sexual function (11 studies), and HRQoL (9 studies). Smith et al. reported that approximately $20 \%$ of patients experienced daytime incontinence, $20 \%$ experienced nighttime incontinence, and 10-20\% experienced hyper-continence. Sexual function appeared to be better among patients who underwent genitalia-sparing $\mathrm{RC}$, but-in general-poor outcomes were noted among those who underwent routine RC. In addition, differences in HRQoL appeared to be minimal between patients who underwent different urinary diversion procedures. Yet, comparisons between patients and the general population revealed significant differences in emotional problems, role functioning, fatigue, and appetite. However, all studies included in this systematic review had a high risk of bias and ranged significantly in sample size, inclusion criteria, and follow-up time.

In a cross-sectional study, female patients reported better sexual function compared with male patients. Female sexual function may be influenced by body perception and changes in body image, whereas male patients may experience problems with erectile and ejaculatory function (36). In this study, the authors observed that, compared to men, women who underwent the IC method presented with poorer cognitive function (mean \pm SD: $77.3 \pm 27.9$ vs. $87.8 \pm 18.6$ ) and future perspective $(42.4 \pm 34.4$ vs. $21.9 \pm 24.6)$ scores. Nevertheless, men who underwent the IC method had worse sexual function scores compared to women $(23.3 \pm 24.5$ vs. 7.0 \pm 20.3$)($ all $\mathrm{P}<0.05)$. The female patients experienced a greater burden in terms of cognitive function and future perspective compared to male patients.

Sexual function is also a major concern among sexually active women with MIBC. Neurovascular bundles are located on the lateral walls of the vagina; therefore, damage to the neurovascular bundles during $\mathrm{RC}$ results in impaired sexual function (56). In addition, foreshortening or narrowing of the vagina can occur after $\mathrm{RC}$ because the anterior vaginal wall is commonly removed or damaged along with the bladder. Several surgical techniques have been proposed that preserve sexual function after RC in women (56,57). First, to avoid significant devascularization of the clitoris, surgeons should consider sparing the distal urethra in selected cases. Second, if the tumor has not invaded the bladder neck and trigone, surgeons should consider preserving the anterior wall of the vagina. Third, tubular reconstruction of the vagina preserves vaginal depth and may facilitate pain-free intercourse (21).

Zippe et al. examined sexual function in 27 female patients who underwent RC (with any type of urinary diversion) preoperatively using the validated Female Sexual Function Index (FSFI) (57). In this study, Zippe et al. observed that only $48 \%$ of patients were able to have successful vaginal intercourse postoperatively. Of these patients, $45 \%$ were unable to achieve orgasm, $41 \%$ experienced decreased lubrication, $37.5 \%$ experienced decreased sexual desire, $22 \%$ experienced vaginal pain, and $52 \%$ reported an overall decrease in satisfaction with their sexual life after RC. However, the authors found that FSFI scores were preserved in a subset of female RC patients with neurovascular preservation who had undergone the ONB procedure; comparatively, women whose neurovasculature was not spared had a significant decline after RC. However, well-controlled, properly designed, comparative studies on sexual outcomes following various surgical techniques are lacking. Such comparative studies are needed in future to better understand the optimal methods for preserving sexual function in women.

\section{Summary}

QoL assessment has greatly improved over the past few decades due to the development of several validated BCrelated questionnaires and the recent effort to create 
a dedicated urinary diversion tool in patients who have undergone RC. Nevertheless, there are few welldesigned studies that have evaluated postoperative QoL in $\mathrm{RC}$ patients. However, with the development of psychometrically validated survey instruments, highquality, prospective, longitudinal studies are critically needed in the urologic literature. Data generated by these studies could greatly help explaining informed consent and anticipated changes in QoL for patients who are scheduled to undergo RC.

\section{Acknowledgments}

Funding: This work was supported by the National Research Foundation of Korea (NRF) grant funded by the Korea government (MSIT) (No. 2019R1F1A1058422).

\section{Footnote}

Provenance and Peer Review: This article was commissioned by the Guest Editors (Ja Hyeon Ku, Ho Kyung Seo and Seok Ho Kang) for the series "Muscle-Invasive Bladder Cancer" published in Translational Andrology and Urology. The article has undergone external peer review.

Conflicts of Interest: All authors have completed the ICMJE uniform disclosure form (available at http://dx.doi. org/10.21037/tau.2020.02.01). The series "Muscle-Invasive Bladder Cancer" was commissioned by the editorial office without any funding or sponsorship. The authors have no other conflicts of interest to declare.

Ethical Statement: The authors are accountable for all aspects of the work in ensuring that questions related to the accuracy or integrity of any part of the work are appropriately investigated and resolved.

Open Access Statement: This is an Open Access article distributed in accordance with the Creative Commons Attribution-NonCommercial-NoDerivs 4.0 International License (CC BY-NC-ND 4.0), which permits the noncommercial replication and distribution of the article with the strict proviso that no changes or edits are made and the original work is properly cited (including links to both the formal publication through the relevant DOI and the license). See: https://creativecommons.org/licenses/by-nc-nd/4.0/.

\section{References}

1. Jung KW, Won YJ, Oh CM, et al. Prediction of Cancer Incidence and Mortality in Korea, 2017. Cancer Res Treat 2017;49:306-12.

2. Svatek RS, Hollenbeck BK, Holmang S, et al. The economics of bladder cancer: costs and considerations of caring for this disease. Eur Urol 2014;66:253-62.

3. Spiess PE, Agarwal N, Bangs R, et al. Bladder Cancer, Version 5.2017, NCCN Clinical Practice Guidelines in Oncology. J Natl Compr Canc Netw 2017;15:1240-67.

4. Stimson CJ, Chang SS, Barocas DA, et al. Early and late perioperative outcomes following radical cystectomy: 90-day readmissions, morbidity and mortality in a contemporary series. J Urol 2010;184:1296-300.

5. Månsson A, Davidsson T, Hunt S, et al. The quality of life in men after radical cystectomy with a continent cutaneous diversion or orthotopic bladder substitution: is there a difference? BJU Int 2002;90:386-90.

6. Caffo O, Fellin G, Graffer U, et al. Assessment of quality of life after cystectomy or conservative therapy for patients with infiltrating bladder carcinoma. A survey by a selfadministered questionnaire. Cancer 1996;78:1089-97.

7. Hedgepeth RC, Gilbert SM, He C, et al. Body image and bladder cancer specific quality of life in patients with ileal conduit and neobladder urinary diversions. Urology 2010;76:671-5.

8. Anderson CB, Feurer ID, Large MC, et al. Psychometric characteristics of a condition-specific, health-related quality-of-life survey: the FACT-Vanderbilt Cystectomy Index. Urology 2012;80:77-83.

9. Gilbert SM, Dunn RL, Hollenbeck BK, et al. Development and validation of the Bladder Cancer Index: a comprehensive, disease specific measure of health related quality of life in patients with localized bladder cancer. J Urol 2010;183:1764-9.

10. Siracusano S, Niero M, Lonardi C, et al. Development of a questionnaire specifically for patients with Ileal Orthotopic Neobladder (IONB). Health Qual Life Outcomes 2014;12:135.

11. Gilbert SM, Wood DP, Dunn RL, et al. Measuring health-related quality of life outcomes in bladder cancer patients using the Bladder Cancer Index (BCI). Cancer 2007;109:1756-62.

12. Aaronson NK, Ahmedzai S, Bergman B, et al. The European Organization for Research and Treatment of Cancer QLQ-C30: a quality-of-life instrument for use in 
international clinical trials in oncology. J Natl Cancer Inst 1993;85:365-76.

13. Cella DF, Tulsky DS, Gray G, et al. The Functional Assessment of Cancer Therapy scale: development and validation of the general measure. J Clin Oncol 1993;11:570-9.

14. Cella D. FACIT manual: Manual of the Functional Assessment of Chronic Illness Therapy (FACIT) measurement system. Center on Outcomes, Research and Education; 1997.

15. Ware JE Jr, Sherbourne CD. The MOS 36-item shortform health survey (SF-36). I. Conceptual framework and item selection. Med Care 1992;30:473-83.

16. Philip J, Manikandan R, Venugopal S, et al. Orthotopic neobladder versus ileal conduit urinary diversion after cystectomy--a quality-of-life based comparison. Ann R Coll Surg Engl 2009;91:565-9.

17. Ali AS, Hayes MC, Birch B, et al. Health related quality of life (HRQoL) after cystectomy: comparison between orthotopic neobladder and ileal conduit diversion. Eur J Surg Oncol 2015;41:295-9.

18. Michels CTJ, Wijburg CJ, Abma IL, et al. Translation and validation of two disease-specific patient-reported outcome measures (Bladder Cancer Index and FACT-Bl-Cys) in Dutch bladder cancer patients. J Patient Rep Outcomes 2019;3:62.

19. Degboe A, Ivanescu C, Rohay JM, et al. Validity and performance of the Functional Assessment of Cancer Therapy-Bladder (FACT-Bl) among advanced urothelial cancer patients. Support Care Cancer 2019;27:4189-98.

20. Zahran MH, Sheir K, Zidan EM, et al. Validation of the Arabic version of the Functional Assessment of Cancer Therapy-Bladder questionnaire in Egyptian patients with bladder cancer. Arab J Urol 2017;15:110-4.

21. Tyson MD 2nd, Barocas DA. Quality of Life After Radical Cystectomy. Urol Clin North Am 2018;45:249-56.

22. Gerharz EW. Re: Hautmann RE, Abol-Enein H, Hafez K, et al: Urinary diversion. Urology 69(suppl): 17-49, 2007. Urology 2008;72:231-2; author reply 2.

23. Lee RK, Abol-Enein H, Artibani W, et al. Urinary diversion after radical cystectomy for bladder cancer: options, patient selection, and outcomes. BJU Int 2014;113:11-23.

24. McAlpine K, Lavallée LT, Stacey D, et al. Development and Acceptability Testing of a Patient Decision Aid for Urinary Diversion with Radical Cystectomy. J Urol 2019;202:1001-7.

25. Nieuwenhuijzen JA, de Vries RR, Bex A, et al. Urinary diversions after cystectomy: the association of clinical factors, complications and functional results of four different diversions. Eur Urol 2008;53:834-42; discussion 42-4.

26. Ghosh A, Somani BK. Recent Trends in Postcystectomy Health-related Quality of Life (QoL) Favors Neobladder Diversion: Systematic Review of the Literature. Urology 2016;93:22-6.

27. Kikuchi E, Horiguchi Y, Nakashima J, et al. Assessment of long-term quality of life using the FACT-BL questionnaire in patients with an ileal conduit, continent reservoir, or orthotopic neobladder. Jpn J Clin Oncol 2006;36:712-6.

28. Sogni F, Brausi M, Frea B, et al. Morbidity and quality of life in elderly patients receiving ileal conduit or orthotopic neobladder after radical cystectomy for invasive bladder cancer. Urology 2008;71:919-23.

29. Erber B, Schrader M, Miller K, et al. Morbidity and Quality of Life in Bladder Cancer Patients following Cystectomy and Urinary Diversion: A Single-Institution Comparison of Ileal Conduit versus Orthotopic Neobladder. ISRN Urol 2012;2012:342796.

30. Gacci M, Saleh O, Cai T, et al. Quality of life in women undergoing urinary diversion for bladder cancer: results of a multicenter study among long-term disease-free survivors. Health Qual Life Outcomes 2013;11:43.

31. Large MC, Malik R, Cohn JA, et al. Prospective healthrelated quality of life analysis for patients undergoing radical cystectomy and urinary diversion. Urology 2014;84:808-13.

32. Singh V, Yadav R, Sinha RJ, et al. Prospective comparison of quality-of-life outcomes between ileal conduit urinary diversion and orthotopic neobladder reconstruction after radical cystectomy: a statistical model. BJU Int 2014;113:726-32.

33. Mischinger J, Abdelhafez MF, Rausch S, et al. Perioperative morbidity, bowel function and oncologic outcome after radical cystectomy and ileal orthotopic neobladder reconstruction: Studer-pouch versus I-pouch. Eur J Surg Oncol 2018;44:178-84.

34. Gerharz EW, Mansson A, Hunt S, et al. Quality of life after cystectomy and urinary diversion: an evidence based analysis. J Urol 2005;174:1729-36.

35. Lee CT. Quality of life following incontinent cutaneous and orthotopic urinary diversions. Curr Treat Options Oncol 2009;10:275-86.

36. Siracusano S, D'Elia C, Cerruto MA, et al. Quality of life following urinary diversion: Orthotopic ileal neobladder versus ileal conduit. A multicentre study among long- 
term, female bladder cancer survivors. Eur J Surg Oncol 2019;45:477-81.

37. Karvinen KH, Courneya KS, North S, et al. Associations between exercise and quality of life in bladder cancer survivors: a population-based study. Cancer Epidemiol Biomarkers Prev 2007;16:984-90.

38. Vakalopoulos I, Dimitriadis G, Anastasiadis A, et al. Does intubated uretero-ureterocutaneostomy provide better health-related quality of life than orthotopic neobladder in patients after radical cystectomy for invasive bladder cancer? Int Urol Nephrol 2011;43:743-8.

39. Marcus HJ, Hughes-Hallett A, Payne CJ, et al. Trends in the diffusion of robotic surgery: A retrospective observational study. Int J Med Robot 2017;13:e1870.

40. Basto M, Sathianathen N, Te Marvelde L, et al. Patternsof-care and health economic analysis of robot-assisted radical prostatectomy in the Australian public health system. BJU Int 2016;117:930-9.

41. Smith AB, Raynor M, Amling CL, et al. Multi-institutional analysis of robotic radical cystectomy for bladder cancer: perioperative outcomes and complications in 227 patients. J Laparoendosc Adv Surg Tech A 2012;22:17-21.

42. Desai MM, Gill IS, de Castro Abreu AL, et al. Robotic intracorporeal orthotopic neobladder during radical cystectomy in 132 patients. J Urol 2014;192:1734-40.

43. Poch MA, Stegemann AP, Rehman S, et al. Short-term patient reported health-related quality of life (HRQL) outcomes after robot-assisted radical cystectomy (RARC). BJU Int 2014;113:260-5.

44. Sathianathen NJ, Kalapara A, Frydenberg M, et al. Robotic Assisted Radical Cystectomy vs Open Radical Cystectomy: Systematic Review and Meta-Analysis. J Urol 2019;201:715-20.

45. Hussein AA, May PR, Jing Z, et al. Outcomes of Intracorporeal Urinary Diversion after RobotAssisted Radical Cystectomy: Results from the International Robotic Cystectomy Consortium. J Urol 2018;199:1302-11.

46. Brassetti A, Cacciamani G, Anceschi U, et al. Longterm oncologic outcomes of robot-assisted radical cystectomy (RARC) with totally intracorporeal urinary diversion (ICUD): a multi-center study. World J Urol 2020;38:837-43.

47. Parekh DJ, Reis IM, Castle EP, et al. Robot-assisted radical cystectomy versus open radical cystectomy in patients with bladder cancer (RAZOR): an open-label, randomised, phase 3, non-inferiority trial. Lancet 2018;391:2525-36.
48. Kimura S, Iwata T, Foerster B, et al. Comparison of perioperative complications and health-related quality of life between robot-assisted and open radical cystectomy: A systematic review and meta-analysis. Int J Urol 2019;26:760-74.

49. Messer JC, Punnen S, Fitzgerald J, et al. Health-related quality of life from a prospective randomised clinical trial of robot-assisted laparoscopic vs open radical cystectomy. BJU Int 2014;114:896-902.

50. Aboumohamed AA, Raza SJ, Al-Daghmin A, et al. Healthrelated quality of life outcomes after robot-assisted and open radical cystectomy using a validated bladderspecific instrument: a multi-institutional study. Urology 2014;83:1300-8.

51. Bochner BH, Dalbagni G, Sjoberg DD, et al. Comparing Open Radical Cystectomy and Robot-assisted Laparoscopic Radical Cystectomy: A Randomized Clinical Trial. Eur Urol 2015;67:1042-50.

52. Li AY, Filson CP, Hollingsworth JM, et al. PatientReported Convalescence and Quality of Life Recovery: A Comparison of Open and Robotic-Assisted Radical Cystectomy. Surg Innov 2016;23:598-605.

53. Satkunasivam R, Santomauro M, Chopra S, et al. Robotic Intracorporeal Orthotopic Neobladder: Urodynamic Outcomes, Urinary Function, and Health-related Quality of Life. Eur Urol 2016;69:247-53.

54. Hekal IA, El-Bahnasawy MS, Mosbah A, et al. Recoverability of erectile function in post-radical cystectomy patients: subjective and objective evaluations. Eur Urol 2009;5 5:275-83.

55. Smith AB, Crowell K, Woods ME, et al. Functional Outcomes Following Radical Cystectomy in Women with Bladder Cancer: A Systematic Review. Eur Urol Focus 2017;3:136-43.

56. Nandipati KC, Bhat A, Zippe CD. Neurovascular preservation in female orthotopic radical cystectomy significantly improves sexual function. Urology 2006;67:185-6.

57. Zippe CD, Raina R, Shah AD, et al. Female sexual dysfunction after radical cystectomy: a new outcome measure. Urology 2004;63:1153-7.

Cite this article as: Choi H, Park JY, Bae JH, Tae BS. Healthrelated quality of life after radical cystectomy. Transl Androl Urol 2020;9(6):2997-3006. doi: 10.21037/tau.2020.02.01 